\title{
A quem pertence a universalidade? 0 Patrimônio e o Museu à luz da Teoria Pós - Colonial
}

\author{
Who owns the universality? Heritage and Museum in light of Postcolonial theory.
}

DOI: https://doi.org/10.22456/2178-8839. 113893

Mariana Pimenta Bueno Universidade do Estado do Rio de Janeiro, Rio de Janeiro, Brasil maripimentabueno@gmail.com

\section{Resumo}

Diante dos crescentes debates sobre repatriação museológica e a reticência de museus europeus quanto a isso, esta pesquisa tem como objetivo analisar criticamente através da Teoria Pós-Colonial, e por meio da análise de documentos, a suposta universalidade do patrimônio anunciada na Declaration on the importance and value of universal museums, lançada em 2002. Questionando esta característica proposta pelos museus signatários, pergunta-se: seria a conservação do patrimônio um valor ocidental? Posto isto, a hipótese testada é que o documento em questão é uma invocação à manutenção colonial ocidental. Composto por três seções, o artigo apresenta conceitos inseridos no museu, como memória e patrimônio, para compreender como seus significados estão intimamente ligados ao Eurocentrismo, através de normas referentes ao espaço e que podem ser exemplificadas pelo documento previamente citado. Ademais, são utilizadas recomendações feitas pela UNESCO a fim de explicar como a universalidade da norma tização patrimonial e museológica évalidada por esses espaços ocidentais, assim como analisar os pedidos de repatriação de peças museológicas como um desafio ao sistema internacional. Por fim, o objetivo aqui proposto não é apresentar uma resposta final a esta agenda, mas sim trazer à luz e problematizar, dentro da área de Relações Internacionais, a importância deste debate.

Palavras-chave: Museu; Patrimônio; Universalidade; Eurocentrismo;

\begin{abstract}
In face of the rising debate about museological repatriation and the European museums reluctance at the subject, this research has as a goal the critical analysis throughout Postcolonial Theory, and by document analysis the justification about an alleged patrimonial universalism, proclaimed by the Declaration on the importance and value of universal museums, released in 2002. Questioning this characteristic proposed by signatories' museums, I wonder: would the conservation of heritage be a Western value? Therefore, the hypothesis worked here is that the document previously mentioned is an invocation for a Western colonial maintenance. Structured by three sections, this article presents concepts that are within the museum, as memoir and heritage, to comprehend how their meanings are intimately linked to Eurocentrism. Furthermore, recommended documents by UNESCO are used to explain how this universalistic heritage and museological norm is valid though these Western spaces, as well as analyzing heritage requests as a challenge for the International System. At last, the aim is not present a final answer for this agenda, but highlight and discuss, within the field of Internation al Relations field, the importance of this debate.
\end{abstract}

Keywords: Museum; Heritage; Universality; Eurocentrism; 


\section{Introdução}

Assmann (2011) afirma que "O fascínio duradouro pelo tema da memória parece ser uma evidência de que diferentes questões e interesses se cruzam, se estimulam e se condensam” (p. 20). “Os homens morrem porque não são capazes de juntar o começo ao fim”, afirmava o filósofo grego Alcménon de Crotona, mas “Mnemosyne, divindade da memória, permite unir aquilo que fomos, ao que somos e ao que seremos” (CANDAU, 2019,p. 60). A titã da mitologia grega, filha de Gaia e Urano e mãe das nove Musas, detinha o poder da memória e da recordação; era "a voz de um passadoque não pertencia a um indivíduo apenas, nem era pertencente a um todo” (VERNANT,1990, p. 138). No entanto, quem detém a memória do mundo mundano? Esta pergunta complexa e difícil nos leva ao lugar mais tradicional no qual aquela é guardada: o museu.

Dentre as missões do museu, salvaguardar a memória é uma delas. Como exposto por Duncan (1991), busca-se “preservar a herança cultural da comunidade” (p. 91) para criar nesse espaço um laço de identificação entre um objeto e seu observador. Ou ainda, que "todo objeto do passado pode ser convertido em testemunho histórico” (CHOAY, 1999, p. 22) mesmo sem ter intencionalidade, alcançando assim a possibilidade de vislumbrar um passado. No entanto, a ilação mais rememorada é a de Pierre Nora (2008), cujo conceito Lugares de Memória permitiu o enquadramento do museu, uma vez que a memória nãoé espontânea e espaços como esses nos transportam pelo tempo uma memória passadaque,embora nunca inteira, busca-se a completude daquele momento (NORA, 2008). Logo, há nessa reconstrução da memória através dos Lugares de Memória uma dinamicidade própria no que tange ao tempo e, com efeito, "material, simbólico e funcional" (NORA, 2008, p. 33), mas que para alcançarem esse status devem ser revestidos de uma aura simbólica e constituídos por “um jogo da memória e da história” (NORA, 2008, p. 33).

Como citado anteriormente, a arqueologia da palavra memória remonta à Antiguidade, assim como a sua relação com a palavra grega mouseion ou Templo das Musas (DESVALLÉES; MAIRESSE, 2013), que detinha a ciência, o saber e a história. Ainda há, desde esse tempo antigo, a intenção de "proteger e tutelar objetos, procedimento que subentende a prática de guardar conservando" (LIMA, 2012, p. 39), algo que os museus incorporaram. Porém, foi a partir do séculoXVIII que a importância de agregar às peças um sentido para narrar a história de um Estadoe proteger aquelas que validaramo Estado-Nação e sua consolidação foi apreendida. A partir da transformação do Museu do Louvre no século XVIII, considerado um marco dessa mudança, em acessível ao povo e não mais exclusivo às elites (DUNCAN, 1991; ARONSSON; ELGENIUS, 2015; LIMA, 2012), que os museus na Idade Moderna, imbuídos pelo Iluminismo, passaram a exercer o papel de materializar uma memória através da narrativa escolhida para aquela nação, ao mesmo tempo em que deviam apresentar as riquezas de um Estado para os demais (DUNCAN,1991), o que demonstra que "O mundodo museu nunca é estático.” (DUNCAN, 1995, p. 6).

De acordo com Anderson (2008) três instrumentos foram necessários aos colonizadores: o mapa, o censo e o museu. O último legitimou a posição de domínio do colonizador em três tempos: o passado, o presente e o futuro. A luta por um passado e pela inserção na história daqueles localizados fora dessa geografia imaginativa (SAID, 1990), vem nos últimos tempos suscitando um debate sobre repatriação ou restituição de bens culturais (COSTA, 2020; COSTA, 2021) dentro da periferia, assim como no centro - exemplo dado pela ação francesa por meio do Rapport sur la restitution du patrimoine culturel africain (MOURA, 2020). No entanto, há um histórico de contrariedade a pedidos como esses por museus ocidentais, que se consideram enciclopédicos, levando a alguns deles a reunirem-se na redação da Declaration on the importance and value of universal museums, em 2002. Posto isto, identifica-se a pretensão de universalidade do patrimônio, que tem agregado, de acordo com classificação da Organização das Nações Unidas para a Educação, a Ciência e a Cultura - UNESCO-o adjetivo histórico mundial. Porém, como no campo das Relações Internacionais ${ }^{1}$ pode-se analisar

\footnotetext{
1 Como apontado por Christofoletti (2017), no século XX novos temas emergiram no campo, permitindo que produtos culturais também fizessem parte da agenda analítica de Relações Internacionais.
} 
essa construção de universalidade baseada em uma norma de patrimonialização originária de uma epistemologia Ocidental?

Logo, considerando que a memória tem em seu núcleo os verbos lembrar e esquecer (CATROGA, 2001), determinados instrumentos são usados para voltar ao passado e compreendê -lo, tal qual o museu pode oferecer através de uma narrativa museal proposta. Nora (2008) escreveu que "a definição nacional do presente requeria então imperiosamente sua justificação mediante a ilustração do passado" (p. 23). Assim, "na periferia, a independência das novas nações conduziu para a historicidade as sociedades já despertadas de seu sono etnológico pela violentação colonial” (NORA, 2008, p. 8), mas estas têm encontrado resistências, pois a narrativa construída pela metrópole esquece a história que parte de suas colônias ocidentais em detrimento daquilo que se quer lembrar, materializado nas exposições museológicas. Dessa maneira, pergunta-se: seria a conservação do patrimônio um valor ocidental? Assim, a hipótese a ser testada através da análise de documentos é que Declaration on the importance and value of universalmuseums (2002) é uma invocação à manutenção colonial ocidental. Não obstante este debate da universalidade já ser discutido por muitos autores, como por Wallerstein (2007), é importante retomá-lo, especialmente no atual momento em que mais debates nesta "agenda de restituições” (MOURA, 2020) vem ocorrendo. ${ }^{2}$

Este trabalho está dividido em três seções, a fim de compreender a problematização do posicionamento dos museus ocidentais como um exemplo da epistemologia colonial ainda existente. A primeira traçará como a teoria PósColonial pode ser usada para compreender o uso da memória e da história no cenário internacional, seguida da genealogia do patrimônio. Por fim, será analisado o documento Declaration on the importance and value of universalmuseums (2002) — que possui signatários de museus localizados no Ocidente apenas —, que defende que as coleções não pertencem a uma sónação, mas a todas, através da ótica da Teoria Pós-Colonial; assim como documentos derivados de recomendações feitas pela UNESCO — como a Convenção para a Proteção do Patrimônio Mundial, Cultural e Natural, de 1972 — importantes para explicar como a universalidade de um comportamento pode ser visto concretamente por determinadas instituições originárias do conhecimento ocidental validado há anos.

\section{Um passado, duas memórias: como a teoria Pós-Colonial provê uma outra percepção}

Vernant (1990) afirmou que “O “passado” é parteintegrante do cosmo; explorá-loé descobrir o que se dissimula nas profundezas do ser” (p.143). Mas quem define o passado que acessamos? Tal acesso seria universal a todos? Esta seção é dedicada à aproximação entre as críticas ontológicas e epistemológicas pós-coloniais e a criação e apreensão dos tempos, importantes para a construção da memória e presentes nas narrativas museais. Como apontado por Wallerstein (1988), o passado social não é imutável e é compreendido como instável por estar ligado ao tempo presente, que experimenta mudanças. Já Gramsci (2001) indicou que a sociedade política ou Estado tem o domínio de maneira direta que se manifesta na superestrutura ${ }^{3}$, o que permite entender como a hegemonia não estaria presente apenas em uma dominação pelaforça (WILLIAMS, 2003), mas também em uma esfera cultural, influenciando em como as narrativas são contadas, não apenas em como se encara o passado, como também como se entende o tempo presente.

\footnotetext{
${ }^{2}$ Há alguns casos recentes que podem ilustrar esse momento de debate nos diversos campos envolvid os. Um exemplo é que, em 2021 , a Alemanha vem debatendo a devolução e determinou que peças pertencentes a atual Namíbia fossem repatriadas. Já a Holanda determinou a criação de uma comissão para debater a devolução de peças para suas ex-colônias, também em 2021. Aliás, é importante expor a diferença entre repatriação e restituição. Conforme explicado por Costa (2019), a primeira significa no campo da Museologia "devolução de peças a seus contextos originais" (MENESES, 1993, p. 214 apud COSTA, 2019, p. 20); enquanto a segunda está ligada ao caminho delas dentro do "mesmo território ou então como uma medida compensatória, no caso da impossibilidade de resolução de repatriação" (COSTA, 2019, p. 20).

${ }^{3}$ Para Marx (2008) "A totalidade dessas relações de produção constitui a estrutura econômica da sociedade, a base real sobre a qual se eleva uma superestrutura jurídica e política e à qual correspondem formas sociais determinadas de consciência. O modo de produção da vida material condicion a o processo de vida social, política e intelectual. Não é a consciência dos homens que determina a sua ser; ao contrário, é o seu ser social que determina sua consciência.” (p. 47). Por sua leitura, Gramsci explanou que a superestrutura é "como uma realidade objetiva e operante que mantém um nexo indissolúvel com a estrutura” (BIANCHI, 2008, p. 135), sendo fatos históricos reais e não somente abstratos.
} 
Por esta dominação dos tempos, a "visão da história mundial e desenvolvimento [é contada] através de uma narrativa particular ou história sobre o Ocidente e definindo o passado, presente e futuro", podendo ser assim “definida como Eurocentrismo" (KRISHNA, 2009, p. 11, tradução nossa) ${ }^{4}$ — expandido para Ocidental (GROVOGUI, 2006), contrapondo-se ao estereótipo místico Oriente (SAID, 1990; GROVOGUI, 2006). Tal como Said (1990) escreveu, o Orientalismo tem como base de pensamento a diferenciação ontológica e epistemológica entre o Ocidente e Oriente. Portanto, o Oriente enquanto discurso existe por uma hegemonia europeia, pois ele "não está meramentelá” (SAID, 1990, p. 16), refletindo "uma relação de poder, de dominação, de graus variados de uma complexa hegemonia" (SAID, 1990, p. 17) e é vista em instituições e na cultura, garantindo, através de sua hegemonia, uma durabilidade (SAID, 1990).

Enquanto um dos apêndices da história contada pelo Ocidente e seus grandes poderes (GROVOGUI, 2006), a construção imagética pelo olhar europeu promoveuimagens acerca da África e estabeleceu um reconhecimento do sujeito europeu em face do "primitivo" africano (GALLAGHER, 2017): o eu em contraposição ao outro. Doravante tal dualidade, o entendimento eurocêntrico sobre o que seriam e como deveriam se comportar as sociedades, tornou-se a base de uma hegemonia no campo político e do saber, pois o caráter civilizatório seria intrínseco à natureza europeia e o caminho esperado para as demais, ignorando diversos avanços tecnológicos e científicos que sociedades não-europeias alcançaram. Por conseguinte, o Outro foi constituído através do poder, não sendo, portanto, um “fato inerte da natureza” (SAID, 1990, p.16).

Ademais, a racionalidade da época colonial era acompanhada por um sentimentalismo recorrente, remetendo um cuidado que a Europa deveria ter com seus territórios colonizados (GROVOGUI, 2006). Em outras palavras, a metrópole imperialista assumia um papel de mãe racional, que tinha como dever cuidar de seu filho, um selvagem que não poderia ser independente, expondo uma epistemologia racial criada para justificar uma suposta superioridade natural europeia sobre as demais populações, herdada do pensamento herdado do período pré -renascentista (GROVOGUI, 2006).

Diante dessa racionalidade, a narrativa da relação entre colônia e metrópole também foi influenciada. A constituição de uma nação, conforme exposto por Thiesse (2001/2002), passa pela “criação das identidades nacionais [que] consistirá em inventariar este patrimônio comum, isto é, de fato, em inventá-lo” (p. 8) e consequentemente a população se identificará. Esse trabalho pedagógico ${ }^{5}$ descrito pela autora se aproxima ao que Anderson (2008) pontuou sobre a “criação de imagens do estado colonial” (p. 226). Dessa forma, ao levar artefatos para os museus das metrópoles, os colonizadores estavam escrevendo a história do passado dos que colonizaram da maneira que imaginaram efomentando a pretensão de salvaguardar tais objetos nesses espaços. E mais: ao exibirem, criaram uma relação do objeto com o observador dotando tal objeto com um sentido que para o europeu seria admissível a outra cultura, isolando de seu contexto e de sua função (ALPERS, 1991).

Sendo assim, ex-colônias africanas independentes no séculoXX também não teriam o direito de ter o "check list identitário"? ${ }^{6}$ Os pedidos de repatriação que vem ocorrendo nos últimos tempos buscam o retorno de peças localizadas em museus aos seus territórios de origem para que a população também tenha o mesmo direito de se (re)conhecer e de ter um passado escrito por eles mesmos. Porém, há museus presentes no Ocidente que não concordam com isso, tal como o documento que será aqui trabalhado sob a ótica teoria Pós-Colonial: a Declaration on the importance and value of universal museums de 2002.

Há, então, a transferência para o âmbito patrimonial e museológico de uma dualidade já reconhecida pelo mundo europeu entre o eu e o outro; após as conquistas além-mar, os termos emlados opostos dessa arena eram o selvagem

\footnotetext{
${ }^{4}$ Do original "This viewing of world history and development through a particular narrative or story about the West and defining the past, present, and future of the whole world through that perspective may be defined as Eurocentrism".

${ }^{5}$ Este também pode ser observado conforme a descrição de Said (1990): “a cobertura da hegemonia ocidental sobre o Oriente durante o período que começa no final do século XVIII, surge um complexo Oriente adequado para estudos na academia, para exposição no museu, para r econstrução no departamento colonial, para ilustração teórica em teses antropológicas” (p.19).

${ }^{6}$ Thiesse (2002) define como necessário para o check list "ancestrais fundadores, uma história que estabeleça a continuidade da nação através das vicissitudes da história, uma galeria de heróis, uma língua, monumentos culturais e históricos, lugares de memória, uma paisagem típica, um folclore" (p. 8).
} 
versus o civilizado oriundo do Ocidente (LÉVI-STRAUSS, 1952). Como dito anteriormente, tal visão deturpadafora construída por teóricos racistas que afirmavam existir uma superioridade entre raças, recorrendo à questão qualitativa (LÉVI STRAUSS, 1952; SAID, 1990). Pois, aquilo que não fazia parte de uma determinada cultura-no caso a europeia-é selvagem, exótico, sem estar inserido no Contrato Social — visão que acompanhou a experiência colonial, não obstante estivesse presente há mais tempo. ${ }^{7}$ Nessa desmedida comparação, a noção de “falso evolucionismo” (LÉVI-STRAUSS, 1952) tem uma visão de que "outras culturas nos apareceriam como estacionárias, não porque necessariamente o fossem, mas porque a sua linha de desenvolvimento nada significa para nós" (LÉVI-STRAUSS, 1952, p. 10), o que ilustra que o Eurocentrismo determina que "o futuro do mundo todo deve ser o passado e o presente do Ocidente" (KRISHNA, 2009, p. 14, tradução nossa). ${ }^{8}$

Posto isto, as noções de patrimônio e preservação também devem ser enquadradas e analisadas criticamente como fruto desse pensamento ocidental. A teoria Pós-Colonial nos dá instrumentos para isso, pois questiona a percepção da "Europa como proprietária exclusiva da ciência legítima, moral universal e instituições imperativas" (GROVOGUI, 2006, p. 10, tradução nossa) ${ }^{9}$ e superior culturalmente aos demais povos (SAID, 1990). Ou, de maneira mais abrangente, se propõe a questionar uma verdade Ocidental cravada como única. É importante pontuar que o pós -colonialismo não é uno, se apresentando diferentes percepções, mas toda s com um olhar comum: não há superação do colonialismo mesmo após a descolonização, sofrendo efeitos na política local (KRISHNA, 2009), uma vez que a independência dos países africanos a partir da segunda metade do séculoXX não foi sinônimo de liberdade (MBEMBE, 2020).

Logo, há continuidade da violência por formas diversas (ABRAHAMSEN, 2007), como a manutenção de peças espoliadas ao longo do imperialismo e ainda mantidas fora de sua origem, exibidas em narrativas não próprias. Porém, quando um país periférico, descolonizado, requisita a devolução de bens culturais, podemos então compreender que tal ação é uma pretensão de "reinterpretar o sujeito e as histórias coloniais, tal como estes têm sido representados tradicionalmente pelo Ocidente" (Tickner; Arreaza, 2002, p. 22, tradução nossa). ${ }^{10}$ Esta criticidade sobre a ontologia e a epistemologia ocidental permite embasamento para a seção a seguir, com intuito de analisar como o patrimônio reflete uma episteme ocidental.

\section{O uso do patrimônio como regra e valor Ocidental: a Declaration on the importance and value of universal museums}

Qual memória que se "orienta para o passado e avança passado adentro por entre o véu do esquecimento" (ASSMANN, 2011, p. 52)? Tal como exposto por Le Goff (2003), há uma relação entre memória e história, em que “A memória, onde cresce a história, que por sua vez a alimenta, procura o passado para servir o presente e ofuturo. Devemos trabalhar de forma a que a memória coletiva sirva para a libertação e não para a servidão dos homens” (LE GOFF, 2003 apud CHAGAS, 2017, p. 126). Na arena de disputa em que se encontra o passado, a questão sobre conservação do patrimônio pode ser encarada como a materialização da história narrada dentro dos museus ocidentais, através dos objetos retirados de suas antigas colônias aolongo do período de dominação, os quais ainda permanecem em museus que se autoproclamam universais, para manter a narrativa do passado sob seu domínio, reafirmando o que fora dito por Fanon (1968): a história seria “escrita [...] pelos ocidentais e para os ocidentais" (p. 182).

O Patrimônio, que muitas vezes está representado através de bens museológicos, não foge do caráter eurocêntrico, tendo forte presença no mundo ocidental e seu conceito definido tal como hoje advindo do pós -Revolução Francesa (VOGT, 2009). No entanto, a categoria de pensamento de patrimônio, como chamado por Gonçalves (2003), está presente no mundo desde a antiguidade, passando pela Idade Média até chegar ao mundo contemporâneo. Pois, ao

\footnotetext{
${ }^{7}$ A questão da alteridade ainda povoa as discussões antropológicas dentro dos museus. Ver Abreu (2009).

${ }^{8}$ Do original "Eurocentric model, the future of the entire world should be the past and present of the West".

${ }^{9}$ Do original "Europe as exclusive proprietor of legitimate science, universal morals, and imperative institutions".

${ }^{10}$ Do original "reinterpretar al sujeto y la historia coloniales, tal como éstos han sido representados tradicionalmente por Occidente".
} 
"Patrimônio e ao Museu, constituem-se como aspectos fundadores os modelos culturais arcaicos praticados na Antiguidade" (LIMA, 2012, p. 33). O Patrimonium era constituído dos bens transmitidos entre pai — pater familias — e seu primogênito (LIMA, 2012). Sendo assim, a ideia da importância da manutenção desses bens aderiu um significado a este conceito.

Posteriormente, no séculoXVIII, o "senhor do patrimônio" não se restringia a um indivíduo apenas, mas sim a uma nação. Isto ocorreu pela Revolução Francesa, quando houve o desenvolvimento de bem comum que formaria "a riqueza material e moral do conjunto da nação” (ABREU, 2009, p. 34). Sendo assim, os bens que pertenciam à família real francesa foram nacionalizados e expostos ao povo que desconhecia tamanho acervo, anexando ao patrimônio o caráter cultural. Pari passu ao novo senhor, veio a necessidade de salvaguardar tais bens para que estes não sofressemvandalismo, pois era preciso conservar um passado e assim ter uma nova história da nação (ABREU, 2009), sendo no século XIX, “os primeiros conceitos de patrimônio e restauração sãolançados” (CARLAN, 2008, p. 78).

Por fim, no século XX, a questão da preservação do patrimônio ultrapassou as fronteiras de um Estado, tendo "um movimento que, sob tutela da Organização das Nações Unidas (ONU), deu orige m a uma série de normas e iniciativas internacionais para a salvaguarda de bens culturais" (LIMA, 2012, p. 35). Com isso, o "Patrimônio que se limitava a preocupações no nível de cada país, [...], tornou-se objeto de inclusão e tratamento em categoria internacional”, adquirindo caráter universal ao criarem "o título de Patrimônio Mundial [...] conforme a Convenção para a Proteção do Patrimônio Mundial, Cultural e Natural (UNESCO, 1972)” (LIMA, 2012, p. 36). Dessa maneira, "a vertente do pensamento moderno no Ocidente enfatiza outro conceito que funcionará em tensão com a ideia de bem coletivo nacional: o de humanidade” (ABREU, 2009, p. 36). Assim, “o patrimônio nacional, além de constituir uma referência para a construção de uma identidade comum a um povo [...] estaria também referido ao que de melhor a humanidade produziu” (ABREU, 2009, p. 36).

Anderson (2008) apontou que "os museus e a imaginação museologizante são profundamente políticos" (p. 246), em que “o Estado" assumiu o papel de "guardião de uma tradição generalizada, mas também local” (p. 250). Conforme já mencionado, museus ocidentais criaram uma narrativa de nação fosse vista em objetos, fomentando uma identidade não só da metrópole, como também daqueles conquistados. Porém, se é neste espaço que aquilo considerado patrimônio é salvaguardado e exposto, criando um poder cultural e didático acerca da história local e mundial, exercido pelo Ocidente através de seus museus e apoiados por uma historiografia também ocidental, não teriam os países descolonizados a partir da metade do século XX o mesmo direito? Ou ainda, a representação do outro outrora colonizado não deveria ser repensada?

De acordo com a definição dada pela UNESCO, o museu é um tipo de

instituição permanente, sem fins lucrativos, a serviço da sociedade e do seu desenvolvimento, aberta ao público, que adquire, conserva, pesquisa, comunica e exibe o patrimônio material e imaterial da humanidade e de seu ambiente para os propósitos de educação, estudo e entretenimento (UNESCO, 2015).

Similarmente para o International Council of Museums (ICOM), o museu não tem fins lucrativos e é uma “instituição permanente a serviço da sociedade e seu desenvolvimento, aberto ao público, que adquire, conserva, pesquisa, comunica-se e exibe o patrimônio tangível e intangível da humanidade e seu ambiente com propósito de educação, estudo e diversão" (ICOM, 2007, tradução nossa) ${ }^{11}$. Essa aproximação reflete o constante diálogo, mesmo que uma organização não esteja submissa a outra.É importante pontuar que, no âmbito internacional, o debate sobre museu e patrimônio ocorre desde a criação do Escritório Internacional de Museus (OIM), pertencente à Liga das Nações, tendo na Carta de Atenas

\footnotetext{
${ }^{11}$ Do original "A museum is a non-profit, permanent institution in the service of society and its development, open to the public, which acquires, conserves, researches, communicates and exhibits the tangible and intangible heritage of humanity and its environment for the purposes of education, study and enjoyment".
} 
(1931) o primeiro documento entre diversos Estados acerca da importância do patrimônio (LIMA, 2012; OLENDER, 2020). Já com a UNESCO, há diversas recomendações e Convenções acerca da proteção e conservação de patrimônios materiais e imateriais, fora e dentro dos museus do mundo, sendo a agência responsável por "patrimônio e validador dos princípios universais” (MADROÑAL; LEÓN, 2016). Isso corrobora ao apontado por Grovogui (2006), em que o cenário internacional do Ocidente precisa de um "sistema internacional ordenado [...]; (2) uma comunidade internacional de Estados, guiada pelo status e poder de seus membros; e (3) uma sociedade internacional baseada em normas e valores compartilhados. (p. 32 , traduçãonossa)". ${ }^{12}$

Portanto, é esperado pelas instituições relacionadas ao tema que os Estados cumpram com o valor e a norma Ocidental da preservação e da salvaguarda de patrimônios e de estruturas museológicas para abrigá-los, alguns deles considerados pela UNESCO como Patrimônio Mundial ${ }^{13}$. Pois o caráter universal dado a determinadas peças significaria que estas apresentam importância para toda a humanidade na proposta de universalismo advinda do fim da Segunda Guerra Mundial e da criação da UNESCO (ABREU, 2009). Conforme exposto no artigo 7 da Convenção para a Proteção do Patrimônio Mundial, Cultural e Natural acordado durante a Conferência Geral da UNESCO, em 1972, um esforço de proteção entre países acerca do tema ${ }^{14}$ deveria existir, o que ratifica que a sociedade internacional, cujos países estão inseridos, é constituída por valor e norma do patrimônio e preservação, introduzidos por uma estrutura hegemônica ocidental denunciada anteriormente.

Diante das regras impostas pela sociedade internacional no que tange ao patrimônio, pode-se identificar que a "A ideia que um deles (o Ocidente) é a fonte da modernidade e que o outro (o Terceiro-Mundo) [e] deve aprender como se modernizar através da imitação” (KRISHNA, 2009, p. 30, traduçãonossa) ${ }^{15}$ é institucionalizada há muito tempo. O Artigo 1 da Convenção da UNESCO (1972) poderia ser lido como um exemplo disso, pois há uma determinação sobre políticas acerca do patrimônio, seja cultural ou natural, como proteção e conservação, além de pesquisas na área (UNESCO,1972). Assim como o Artigo 6 que estipula, ainda, que considerando a soberania dos Estados e suas leis, a "comunidade internacional tem o dever de cooperar” (UNESCO,1972) para a proteção do patrimônio.

É notório que há um movimento ${ }^{16}$ cada vez mais intenso que põe em xeque a manutenção de bens museológicos em territórios não originários. Conforme já citado, os países africanos buscam a preservação de seus patrimônios em museus próprios e a oportunidade de contar narrativas do mundo por seus objetos autóctones, como nos recentes museus Grande Museu Egípcio, no Cairo, e o Museu das Civilizações Negras, em Dakar. No entanto, há uma permanência na ausência de determinadas peças que relatem seu passado por elas estarem localizadas em alguns museus ocidentais, reforçando que o Ocidente mantém seu poder sob antigas colônias através da cultura.

Uma das reações que se pode citar é a de dezoito museus - todos localizados no Ocidente e boa parte criados entre o século XIX e o início do XX — que assinaram uma declaração pequena, justificando o porquê de se posicionarem contrariamente à repatriação museológica: a Declaration on the importance and value of universal museums (DIVUM). São eles: Instituto de Arte de Chicago; Bavarian State Museum, Munique; State Museums (uma organização guarda-chuva localizada em Berlim); Museu de Arte de Cleveland; Museu J. Paul Getty em Los Angeles; Museu Solomon R. Guggenheim, New York; Los Angeles County Museum of Art; Museu do Louvre, Paris, Metropolitan Museum of Art, Nova York; Museu de Belas Artes em Boston; Museu de Arte Moderna, Nova York, Opificio delle Pietre Dure, Florença, Museu de Arte da

\footnotetext{
${ }^{12}$ Do original "orderly international system, or an identifiable structure as context for international relations; (2) an international comm unity of states guided by the status and power of its members; and (3) an international society based on shared norms and values".

${ }^{13}$ Compreende-se como Patrimônio Mundial um conjunto de monumentos, conjuntos arquitetônicos ou sítios "de valor universal excepcional do ponto de vista histórico, estético, etnológico ou antropológico” (UNESCO, 1972).

${ }^{14}$ Segundo o documento, "entende-se por proteção internacional do patrimônio mundial cultural e natural o estabelecimento de sistema de cooperação e de assistência internacional destinado a auxiliar os Estados-partes da Convenção nos esforços empreendidos para preservar e identificar esse patrimônio." (UNESCO, 1972).

${ }^{15}$ Do original "The idea that one of them (the West) is the source of modernity and that the other (the third world) has to learn how to modernize itself through imitation".

${ }^{16}$ Alguns exemplos são a Pedrade Roseta, exposta no Museu Britânico, que o governo egípcio pede pelo retorno (COSTA, 2019; BHAL, 2009) e os mármore s do Parthenon (SMITH, 2009), ambos sem resolução. Já exemplo de devolução foi a estátua Vênus de Cyrene, em que a Itália devolveu à Líbia, nos anos 2000, depois de anos de imbróglio judicial.
} 
Philadelphia, Museu do Prado, Madrid, Rijksmuseum em Amsterdã; State Hermitage Museum, em São Petersburgo; ThyssenBornemisza Museum, Madri; e Whitney Museum of American Art, Nova York (FOCUS, 2004). Esse documento pode ser visto como um absoluto exemplo daquilo que o Ocidente considera racional e de como o "Ocidentalismo então requer a supremacia do Leste (também Ocidente) como um requisito necessário da racionalidade política e moralidade e ordem internacional” (GROVOGUI, 2006,p. 28, traduçãonossa). ${ }^{17}$

Na DIVUM, os museus se posicionam que não são contra ao combate ao tráfico ilícito de peças museológicas, mas que não são a favor da repatriação: “No entanto, nós devemos reconhecer que esses objetos adquiridos em tempos anteriores devem ser vistos à luz de diferentes sensibilidades e valores, refletida naquela era anterior” (FOCUS, 2004, traduçãonossa $)^{18}$. E continua afirmando que “os objetos e trabalhos monumentais que foram instalados há décadas e até mesmo séculos atrás nos museus aolongo da Europa e América foram adquiridos sob condições que não são comparáveis no momento atual”"19 (FOCUS, 2004, tradução nossa), levantando o pertencimento desses bens a uma memória nacional de seus países e como essas peças contariam uma narrativa de seu tempo, uma vez que "objetos então adquiridos — seja por compra, presente ou divisão — se tornaram parte dos museus que deles cuidam e por extensão parte da patrimônio das nações que os abrigam” (FOCUS, 2004, traduçãonossa). ${ }^{20}$

Não obstante entenderem o momento, os museus ocidentais signatários continuam seu argumento afirmando que essas peçasjá estãolonge de suas origens há tempos e que não haveria uma admiração pela arte de civilizações antigas se os exemplares destas não estivessem em importantes museus que recebem pessoas do mundo todo (FOCUS, 2004, traduçãonossa). Afinal, os “museus servem não apenas aos cidadãos de uma nação, mas sim às pessoas de qualquer nação. Museus são agentes no desenvolvimento da cultura, cuja missão é promover conhecimento através do processo contínuo de reinterpretação" (FOCUS, 2004, traduçãonossa). ${ }^{21}$

Nessa disputa sobre o passado, as instituições que salvaguardam as normas e os direitos são aquelas criadas no Ocidente que são compreendidas como instrumentos para seus objetivos. Logo, os museus do Ocidente assumem dois papéis: o de protetor de uma cultura universal ${ }^{22}$, que deve ser preservada de acordo com os padrões obedecidos pelos museus ocidentais; e o de modelo a ser seguido que contém as normas da UNESCO. Ambos se aproximam do papel que a Europa criou para si e que ganhou força na época do Imperialismo: o de "salvadora e líder do mundo" (GROVOGUI, 2006, p. 27, tradução nossa). ${ }^{23}$ Ao mesmo tempo, rompem com a compreensão tanto da UNESCO, quanto do ICOM, em que esses espaços estão a serviço da sociedade, uma vez que consideram tal acessibilidade para as suas e para aqueles que podem viajar até esses países.

Em suma, a universalidade ainda em vigor é a oriunda do Ocidente. Como questionado por Burlingame (2014): "se museus "universais” são somente encontrados na Europa e na América do Norte, [...] tecnicamente direcionados e acessíveis apenas para os cidadãos da América do Norte e Europa; então, como exatamente eles definem 'universal'?” (p. 386, traduçãonossa). ${ }^{24}$ Dessa maneira, pode-se fazer uma ilação com a exposição de Grovogui (2006) acerca dos Cânones Ocidentais sendo a "base do entendimento internacional e moralidade" (p. 41, tradução nossa) ${ }^{25}$, assim comoum exemplo

\footnotetext{
${ }^{17}$ Do original "Occidentalism thus requires the supremacy of the West (also Occident) as a necessary requirement of political rationality and international order and morality".

${ }^{18}$ Do original "We should, however, recognize that objects acquired in earlier times must be viewed in the light of different sensitivities and values, reflective of that earlier era”.

${ }^{19}$ Do original "The objects and monumental works that were installed decades and even centuries ago in museums throughout Europe and America were acquired under conditions that are not comparable with current ones".

${ }^{20}$ Do original "objects so acquired - whether by purchase, gift, or partage-have become part of the museums that have cared for them, and by extension part of the heritage of the nations which house them".

${ }^{21}$ Do original "museums serve not just the citizens ofone nation but the people of every nation. Museums are agents in the development of culture, whose mission is to foster knowledge by a continuous process of reinterpretation".

${ }^{22}$ Arronsson (2015) expõe que diversos museus de intitularam como museus universais no século XXI para se protegerem dos "pedidos de repatriação baseados no contexto nacional cultural como um forte reivindicação de direitos legítimos” (L.191, tradução nossa).

${ }^{23}$ Do original "savior and leader of the world".

${ }^{24}$ Do original "However, if 'universal' museums are only found in Europe and North America, they are technically only directly and accessibly serving citizens of North America and Europe; so, how exactly do they define 'universal?".

${ }^{25}$ Do original "basis of international understanding and morality".
} 
da hegemonia exercida pela Europa em seu papel de líder cultural (SAID, 1990). Pois, visto a experiência europeia acerca de preservação de patrimônio e como um museu deve ser, todos os países devem adotar determinados me canismos, como os estipulados pelas convenções da UNESCO. Burlingame (2014) também pontuou que, ao ter sido lançada, DIVUM despertou questionamentos dentro e fora do Ocidente ${ }^{26}$, mesmo sem haver uma definição precisa. ${ }^{27}$ Aos museus universais pressupõe-se que se entendam como fundamentais em um cenário, uma vez que "objetos conservados em "museus importantes” não deveriam ser tão universalmente admiráveis se eles não são dispostos para o público ver” (BURLINGAME, 2014, p. 386, traduçãonossa). ${ }^{28}$. Portanto, a universalidade em que determinados museus argumentam se enquadrar obedece um padrão de comportamento e cumprimento de regras esperados apenas em determinados espaços localizados no Ocidente, reiterando sua hegemonia em diversas estruturas, tal como a ideia que os museus Orientais não teriam a capacidade de preservar e de terem instalações aptas para receber essas peças requisitadas, como declararam os museus signatários.

Do lado oposto a esse discurso, encontra-se o Museu das Civilizações Negras (MCN), localizado em Dakar, Senegal, e inaugurado em 2018, com uma moderna estrutura. Este museu inspira -se em uma ideia exposta durante o conselho ministerial no Senegal, presidido pelo então presidente senegalês, Leopold Senghor, em 1974, para a construção de Musée négro-africain e promover Dakar como capital da cultura. Defendia que a negritude "era tambémuma expressão da filosofia a ser lida nos produtos culturais da África” (DIAGNE, 2016, pag. Irre, tradução nossa) ${ }^{29}$ (MCN,2021), ideal mantido pelo MCN, cuja “origem está ancorada nas raízes ideológicas da negritude diante de uma desvalorização dos legados, das histórias tecnológicas e culturais das civilizações negras”. ${ }^{30}$ Um exemplo é explorar o continente africano como berço da civilização, proposta da exposição em curso L'Afrique berceau del'Humanité, o que permitiria "deslocar a Europa do centro da história e da consciência, a fim de acomodar as experiências de outros” (GROVOGUI, 2006, p. 54, tradução nossa). ${ }^{31}$ Além disso, dois objetivos foram pensados para este:não ser um museu apenas etnográfico e ser a vitrine que expõe a vitalidade do continente africano (DUMONT; CHAVEROU, 2020), rompendo assim com a imagem construída pelos europeus, de um lugar que não pode se proteger sozinho.

Logo, pode-se analisar este museu como um caso que objetiva romper com um laço imperialista, através deuma nova perspectiva de museu na periferia, que incluiria a reclamação de peças originárias do continente que permanecem expostas em museus europeus, com “a ideia de uma restituição para o continente de seu patrimônio cultural” (LE MONDE, 2018, tradução nossa). ${ }^{32}$ Por outro lado, responde às adequações propostas pelas normas da UNESCO e ICOM, demonstrando que um museu fora do eixo geográfico eurocêntrico, tem a mesma capacidade material e técnica dos museus ocidentais.

\section{Conclusão}

Para Karp (1991), os museus são um aparato de poder, uma vez que não há neutralidadena escolha daquilo que será expostoe, como uma instituição ocidental, promoveu uma (perda da) "aura” ${ }^{33}$ ao exibir peças que estãonos museus como troféus do imperialismo. Ao expor, museus ocidentais transformaram por vezes o objeto retirado de suas ex-colônias em algo a ser visto e controlando como ambos os territórios eram vistos — o colonizador como poderoso e o colonizado

\footnotetext{
${ }^{26}$ Para Geoffrey Lewis, membro do Comitê Ético do ICOM, "The real purpose of the Declaration was, however, to establish a higher degree of immunityfrom claims for the repatriation of objects from the collections of these museums. The presumption that a muse um with universally defined objectives may be considered exempt from such demands is specious. The Declaration is a statement of self-interest, made by a group representing some of the world's richest museums" (2004).

${ }^{27}$ Cuno (2008) possui um conceito similar a essa ideia; museus enciclopédicos seriam "repository of things and knowledge" (CUNO, 2008 apud BURLINGAME, 2014, p. 390).

${ }^{28}$ Do original "objects held in 'major museums' would not be so universally admired if they were not displayed for the public to view."

${ }^{29}$ Do original "was also the expression of a philosophy to be read in the cultural products of Africa"(DIAGNE, 2016, pag. irre.).

${ }^{30}$ Do original "Son origine s'ancre dans les racines idéologiques de la Négritude face à une dévalorisation des héritages, historiques technologiques et culturels des civilisationsnoires".

${ }^{31}$ Do original "aim was to displace Europe from the center of history and consciousness in order to accommodate the experiences of others".

${ }^{32}$ Do original "l'idée d'une restitution au continent de son patrimoine culturel" (Le Monde, 2018).

${ }^{33}$ Remete ao conceito de Walter Benjamin (1955).
} 
como passível de dominação — se apropriando de seus significados (VOGEL, 1991; ALPERS, 1991). No entanto, os últimos movimentos de países centrais acerca da devolução suscitam debates que devem ser pensados: quem determina o acervo a ser devolvido, o ex-colonizador ou o ex-colonizado? Quem arcará com os custos dessas operações?

Ao reclamarem pelo direito ao patrimônio como memória de um povo, os países africanos vêm reclamar a gerência de sua história. Karp (1991) afirmou que embora os debates sobre representações em exibições em museus tenham surgido dentro do modelo estipulado pelo Ocidente, não houve questões fundamentais como "exibição enquanto agente e configuração para a representação” (p. 12, tradução nossa) ${ }^{34}$. Nessa esteira de problematização, o próprio ICOM vem buscando respostas mediante essas agendas atuais, considerando a redefinição do que seja um museu (ICOM, 2019).

É notória a importância da criação de mecanismos e espaços para a conservação de patrimônios que são considerados importantes para a humanidade; isto não deve ser ignorado por nenhum museu. No entanto, a problematização aqui proposta é que também não se pode desconsiderar que essas normas e valores foram dados de acordo com o que o Ocidente considera importante. A teoria Pós-Colonial auxilia nas pesquisas que envolvem cultura, pois traz temas tradicionalmente marginalizados nas Relações Internacionais para ser o foco dos estudos (ABRAHAMSEN, 2007). Além disso, isso permite analisar que alguns museus ocidentais defendem a permanência de peças de suas ex colônias, como mostra a DIVUM, baseando-se em argumentos eurocêntricos.

Em síntese, a Declaration on the importance and value of universal museums reflete a ideia de que o Ocidente é capaz de cuidar dos bens culturais de toda humanidade, assim comoignora a trajetória desses bens até as exposições nos museus Orientais. Para Chagas (2002) "Preservar e destruir, musealizar ou não musealizar, memorizar e esquecer formam pares bailarinos desenhando no tempo e no espaço uma coreografia esquisita” (pag. irre.), mas quem são os bailarinos não se sabem; o que se sabe é que tais ações ocorrem por sujeitos que desejam cada uma delas. Ao requisitarem seus patrimônios, o colonizado se torna um sujeito capaz de ser o agente de sua vida. Enquanto está sendo categorizado como Outro, esse sujeito está inserido em uma estrutura que fora constituída através do poder. Logo, há um desafio ao sistema internacional estruturado com a ideia de que o Ocidente é o detentor do conhecimento e da história. Por isso, tal como defendidopor El Hadji Malick Ndiaye (KLITZING, 2021), é de suma importância a participação efetiva de museus no Oriente para que de fato o continente africano tenha gerência sobre seu patrimônio. Como dito no início deste trabalho, não há respostas fechadas e definitivas, mas sim o vislumbre do crescente desejo de romper com esse últimolaço imperialista por parte da Periferia Global ou o Oriente.

\section{Referências}

ABREU, Regina. A emergência do patrimônio genético e a nova configuração do campo do patrimônio. In CHAGAS, Mario; ABREU, Regina (orgs). Memória e Patrimônio: ensaios contemporâneos. Rio de Janeiro: Lamparina, 2009. P. 34 - 48.

ABRAHAMSEN, Rita. Postclonialism. In GRIFFITHS, Martin (ed). International Relations Theory for the Twenty-First Century. Routledge. 2007,Cap. 10, p. 111-122.

ALPERS, Stvetlana. "The Museum as a Way of Seeing. In KARP, Ivan; LAVINE, Steven (eds). Exhibiting Cultures: the poetics and politics of Museum Display. Washington: Smithsonian Institution Press. 1991. Cap. 1, p. 25-32.

ASSMANN, Aleida. Espaços de Recordação. Formas e transformação da memória cultural. Campinas: Editora Unicamp. 2011.

ARRONSON, Peter. National Museums as cultural constitutions. In ARRONSON, Peter; ELGENIUS, Gabriela (Orgs.) National Museums and Nation-Building in Europe 1750-2010. Nova York: Routledge, 2015. (E-book)

BHAL, Harpreet. "Egypt to ask British Museum for Rosetta Stone”. Reuters Life! Londres, 14 de dez. de 2009. Disponível em https://br.reuters.com/article/idUSTRE5BD2GR20091214. Acesso em 30 jan. 2021.

BIANCHI, Alvaro. O laboratório de Gramsci: filosofia, história e política. São Paulo: Alameda, 2008.

BURLINGAME, Katherine. Universal Museums: Cultural and Ethical Implications. Conference Proceedings the Right to [World] Heritage. BTU Cottbus - Senftenberg 2014. Disponível em

\footnotetext{
${ }^{34}$ Do original "the exhibition as a médium of and setting for representation".
} 
https://www.researchgate.net/profile/Katherine_Burlingame/publication/299594822_Universal_Museums_Cultural_and_Ethical_Im plications/links/57015ca208ae1408e15ea672/Universal-Museums-Cultural-and-Ethical-Implications.pdf?origin=publication_detail. Acesso em 03 jan. 2021.

CANDAU,Joël. Memória e identidade. São Paulo: Contexto, 2011.

CARLAN, Claudio Umpierre. Os Museus e o Patrimônio Histórico: uma relação complexa. História. São Paulo, v. 27, n. 2, p. 75-88, 2008. Disponível em: https://doi.org/10.1590/S0101-90742008000200005. Acesso em 16 jan. 2021.

CATROGA, Fernando. Recordação e esquecimento. In CATROGA, F. Memória, História e Historiografia. Coimbra: Quarteto Editora, 2001.

CHAGAS, Mario. Cultura, Patrimônio e Memória. Ciências e Letras, Porto Alegre,v. 31, p. 15-29, 2002.

CHAGAS, Mario. Museus e Patrimônios: por uma poética e uma política decolonial. Revista do patrimônio histórico e artístico nacional, n. 35, 2017.

CHOAY, Françoise. A Alegoria do Patrimônio. Unesp, 2001.

CHRISTOFOLETTI, Rodrigo. Patrimônio como esteio das Relações Internacionais. In CHRISTOFOLETTI, Rodrigo (Ed.). Bens culturais e relações internacionais: o patrimônio como espelho do soft power. Editora universitária Leopoldianum, 2017. Introdução, p. 1340 .

COSTA, Karine Lima da. A demanda pela restituição do patrimônio cultural através das relações entre a África e a Europa. Locus: Revista de História, Juiz de Fora, v. 26, n. 2, p. 193-209,2020. Disponível em: https://periodicos.uff.br/index.php/locus/article/view/31068. Acesso em: 7 maio. 2021.

COSTA, Karine Lima da. Caminhos para a descolonização dos museus: a questão da repatriação das antiguidades egípcias. Tese (Doutorado em História) - Universidade Federal de Santa Catarina, Florianópolis, Brasil, 2019, 294 p.

DESVALLÉES, André; MAIRESSE, François Conceitos-chave de Museologia. São Paulo: Comitê Brasileiro do Conselho Internacional de Museus: Pinacoteca do Estado de São Paulo: Secretaria de Estado da Cultura, 2013

DIAGNE, Souleymane B. Négritude. In:ZALTA, Edward N. (ed.). The Stanford Encyclopedia of Philosophy (Spring 2016 Edition). Center for the Study of Language and Information (CSLI), Stanford University. Disponível em https://plato.stanford.edu/archives/spr2016/entries/negritude/

DUMONT, Laetitia; CHAVEROU, Éric. Musée des civilisations noires de Dakar: un panafricanisme revendiqué. France Culture. 14 ago. 2020. Disponível em: https://www.franceculture.fr/geopolitique/musee-des-civilisations-noires-de-dakar-un-panafricanisme-revendique. Acesso em 15 jul. 2021.

DUNCAN, Carol. Art Museums and the Ritual of Citizenship. In KARP, Ivan; LAVINE, Steven (eds). Exhibiting Cultures: the poetics and politics of Museum Display. Washington: Smithsonian Institution Press.1991. Cap. 6, p. 88-103.

DUNCAN, Carol. Civilizing rituals: Inside public art museums. Routledge, 2005.

GALLAGHER, Julia (ed). Images of Africa: creation, negotiation and subversion. Manchester: Manchester University Press, 2015

GONÇALVES, José Reginaldo S. O Patrimônio como categoria de pensamento. In CHAGAS, Mario; ABREU, Regina (orgs). Memória e Patrimônio: ensaios contemporâneos. Rio de Janeiro: Lamparina, 2009. P.25-33.

GRAMSCI, Antonio. Cadernos do Cárcere. Volume 2. $2^{\mathrm{a}}$ ed. Rio de Janeiro: Editora Civilização Brasileira, 2001.

GROVOGUI, Siba N. Beyond Eurocentrism and anarchy: memories of international order and institutions. New York: Palgrave Macmillan. 2006.

FANON, Frantz. Sobre a Cultura Nacional. In FANON, Frantz. Os Condenados da Terra. Rio de Janeiro: Editora Civilização Brasileira. 1968. Cap. 4, p. 169-196.

FOCUS. Declaration on the importance and value of universal museums. ICOM News. 2004 Disponível em: http://network.icom.museum/fileadmin/user_upload/pdf/ICOM_News/2004-1/ENG/p4_2004-1.pdf. Acesso em 12 fev. 2021.

FOCUS. "ICOM announces the alternative museum definition that will be subject to a vote". ICOMNews 25 de.jul. 2019. Disponív el $\mathrm{em}:$ https://icom.museum/en/news/icom-announces-the-alternative-museum-definition-that-will-be-subject-to-a-vote/. Acesso em 15 jul. 2021.

KLITZING, Isabel Von. "Why African voices are crucial to the debate over the return of colonial loot" The Art Newspaper. 26 de mar. 2021. Disponível em: https://www.theartnewspaper.com/interview/why-african-voices-are-crucial-to-the-restitution-debate. Acesso em 29 de mar. 2021

KRISHNA, Sankaran. Globalization and Postcolonialism: Hegemony and Resistance in the Twenty-first Century. Maryland: Rowman \& Littlefield Publishers, Inc. 2009 
“Le Sénégal inaugure un Musée des civilisations noires à Dakar”. Le Monde, 05 de dez. 2018.. Disponível em: https://www.lemonde.fr/afrique/article/2018/12/05/le-senegal-inaugure-un-musee-des-civilisations-noires-adakar_5392879_3212.html. Acesso em: 12 jul. 2021.

LEWIS, Geoffrey. The Universal Museum: a Special Case? Icom news. Paris, 2004. Disponível em: https://icom.museum/en/ressource/the-universal-museum-a-special-case/.Acesso em 02 jan. 2020.

LIMA, Diana Farjalla Correia. Museologia-Museu e Patrimônio, Patrimonialização e Musealização: ambiência de comunhão. Boletim do Museu Paraense Emílio Goeldi. Ciências Humanas, Belém,v. 7, n. 1, p. 31-50,2012. Disponível em: https://doi.org/10.1590/S1981-81222012000100004. Acesso em 19 jan. 2021.

MARX, Karl. Prefácio. In MARX, Karl. Contribuição Crítica à uma Economia Política. São Paulo: Expressão Popular, 2008. P. 45 -50.

MADROÑAL,Ángeles Castaño; LEÓN, Elodia Hernandéz. As políticas patrimoniais da UNESCO na geopolítica de colonialidades globais e a emergência de novos sentidos de interculturalidade do patrimônio na Andaluzia. OPSIS: Revista do Departamento de História e Ciências Sociais, 16 (1), p. 131-152, 2016. Disponível em: https://doi.org/10.5216/o.v16i1.37021. Acesso em: 15 jul. 2021.

MOURA, Sabrina. Museus, Identidades e Gestos Políticos na Agenda das Restituições. In COSTA, Paulo de Freitas; COSTA, Ana Cristina Moutela (org.). Cadernos da Casa Museu Ema Klabin: identidades paulistanas. São Paulo: Fundação Cultural Ema Klabin, p. 25-35. 2020.

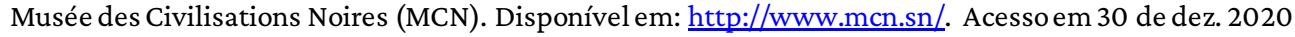

NORA, Pierre. Leux lieux de la mémoire. Montevideo: Editoras Trilce, 2008.

OLENDER, M. "O abismo da história é grande o suficiente para todos". Os primórdios da Carta de Atenas de 1931 e a afirmação da noção de patrimônio da humanidade. Locus: Revista de História, Juiz de Fora, v. 26, n. 2, p. 291-313, 2020. DOI:10.34019/2594-

8296.2020.v26.31204. Disponível em:https://periodicos.uff.br/index.php/locus/article/view/31204. Acesso em:13 out. 2020.

SAID, Edward. Orientalismo: o Oriente como invenção do Ocidente. São Paulo: Companhia das Letras, 1990.

SMITH, Helena. "Greece demands return of stolen heritage". The Guardian, Atenas, 11 de jul. de 2006. Disponível em: https://www.theguardian.com/world/2006/jul/11/parthenon.arttheft. Acesso em 30 jan. 2021.

STRAUSS, Claude Lévi. Raça e história. Antropología estructural, 1952.

TICKNER, Arlene B. e ARREAZA, Catalina. Postmodernismo, postcolonialismo y feminismo: manual para (in)expertos. Colombia Internacional, v. 54 p.14-38, 2002. Disponível em: https://doi.org/10.7440/colombiaint54.2002.01. Acesso em: 30 out. 2020.

UNESCO. Convenção para a Proteção do Patrimônio Mundial, Cultural e Natural. 1972. Disponível em: https://unesdoc.unesco.org/ark:/48223/pfo000133369_por. Acesso em 29 dez. 2020.

UNESCO. Recomendação Referente À Proteção E Promoção Dos Museus E Coleções, Sua Diversidade E Seu Papel Na Sociedade. 2015. Disponível em: https:/www.museus.gov.br/wp-content/uploads/2016/11/Unesco_Recomendacao-Final_POR-traducao-naooficial.pdf . Acesso em 27 dez. 2020.

VERNANT, Jean-Pierre. Mito e pensamento entre os gregos: estudos de psicologia histórica. Rio de Janeiro: Paz e Terra, 1990.

VOGEL, Susan. Always true to the Object, in Our fashion. In KARP, Ivan; LAVINE, Steven (eds). Exhibiting Cultures: the poetics and politics of Museum Display. Washington: Smithsonian Institution Press.1991. cap. 12, p. 191-204.

VOGT, Olgário Paulo. Patrimônio cultural: um conceito em construção. Dossiê MÉTIS: história \& cultura. Caxias do Sul, v. 7, n. 13, p. 13-31, 2008. Disponível em: http://www.ucs.br/etc/revistas/index.php/metis/article/view/687. Acesso em: 18 jan. 2021.

WALLERSTEIN, Immanuel. O universalismo europeu: a retórica do poder. São Paulo, Boitempo Editoral, 2007.

WILLIAMS, Raymond. Palabras clave: um vocabulário y la sociedade. Buenos Aires: Nueva Visión, 2003.

Funções de colaboração exercidas

Mariana Pimenta Bueno:
Conceituação; Metodologia; Validação; Curadoria de dados; Administração do projeto; Visualização; Análise formal; Recursos; Obtenção de financiamento; Investigação; Escrita (primeira redação); Escrita (revisão e edição); 